\title{
Eating Disorders and Intimate Partner Violence: The Influence of Fear of Loneliness and Social Withdrawal
}

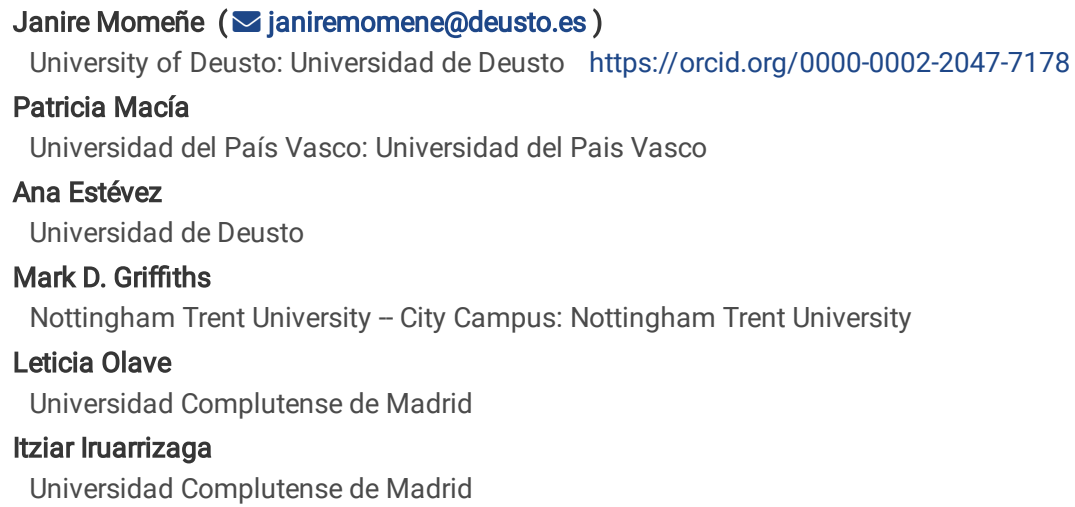

Research Article

Keywords: eating disorders, intimate partner violence, social withdrawal, fear of loneliness, path analysis

Posted Date: February 22nd, 2022

DOI: https://doi.org/10.21203/rs.3.rs-1345777/v1

License: (c) (1) This work is licensed under a Creative Commons Attribution 4.0 International License. Read Full License 


\section{Abstract}

Eating disorders are vulnerability factors that increase the likelihood of intimate partner violence. However, the mechanisms underlying this relationship are unclear. Although eating disorders have been associated with increased perception and fear of loneliness, they have also been associated with increased social withdrawal resulting from decreased enjoyment of social situations and poorer social functioning. The purpose of the present study was to examine the mediating role of fear of loneliness in the relationship between the behavioural characteristics of eating disorders and intimate partner violence, as well as to explore the moderating role of social withdrawal in the relationship between fear of loneliness and intimate partner violence. The sample comprised 683 participants ( $78 \%$ female and $22 \%$ male) with a mean age of 21.14 years $(S D=2.72)$. The hypothesized model was tested by path analysis using maximum likelihood. The path analysis of the hypothesized model showed that inefficacy, fear of maturity, and impulsivity were the behavioural characteristics of eating disorders predominantly related to fear of loneliness. Fear of loneliness had no direct significant effect on any of the received violence variables. However, interaction effects indicated that there was a moderately significant effect of fear of loneliness on physical, psychological, and social violence received as a function of levels of social withdrawal. These findings show the need to take into account and work on fear of loneliness and social withdrawal among individuals with an eating disorder to decrease the likelihood of establishing violent intimate partner relationships. Improving interpersonal functioning and social support is key to recovery from eating disorders.

\section{Introduction}

Eating disorders (Eds) are serious psychiatric disorders (Gorrel \& Murray, 2019) that significantly impair the physical and psychological health of sufferers. Moreover, the mortality rate is one of the highest compared to other psychiatric conditions (5\%-10\%) (Bhattacharya et al., 2020; Jagielska \& Kacperska, 2017). Currently, the main types of eating disorders that individuals suffer from worldwide are anorexia nervosa, bulimia nervosa, and binge eating disorder (Hay, 2020), characterized by persistent disturbance of eating behaviour (Maon et al., 2020). It has been estimated that Eds affect $15 \%$ of the world population and their incidence continues to increase. Moreover, they begin to manifest themselves between early and late adolescence. It is at this stage of the life cycle that important physical, psychological and neuronal changes occur (Aouad et al., 2021). Its aetiology is multifactorial, and psychological, developmental, biological and/or sociocultural factors may influence it. However, the aetiology is not yet fully elucidated. In recent years, the need for further research has been noted (Bhattacharya et al., 2020; Treasure et al., 2020).

In addition to the deterioration produced in physical and psychological health, eating disorders can also negatively impacts social functioning (Brown et al., 2021; Mason et al., 2016; Mason \& Heron, 2016; Mehl et al., 2019). The perception of loneliness has been found to be present in individuals with this problem, and it is considered a negative emotion that contributes to and increases their symptomatology. Moreover, eating disorders also exacerbate feelings of loneliness (Wiedemann et al., 2018). Perceived loneliness is defined as emotional distress stemming from a feeling of rejection or isolation by others or the lack of a social partner to lean on and engage in activities with. Moreover, it has been shown to severely influence individuals' quality of life (Cacioppo \& Cacioppo, 2018; Johnson et al., 2018).

Recent research has highlighted the feeling of loneliness as one of the most commonly present issues among young adults (Pitman et al., 2018). However, very few studies have examined the feeling of loneliness in emerging adulthood (Arnett et al., 2014) and even fewer in Spain (where the present study was carried out) in relation to eating disorders. Understanding the relationship between eating disorders and fear of loneliness is vital to address these intense emotions within prevention and treatment programs. Therefore, it is important to analyse the impact exerted by the fear of loneliness among individuals with this problem (Peaslee, 2012; Wiedemann et al., 2018).

In addition, previous studies have noted the use of dysfunctional coping strategies by individuals with an ED (Han et al., 2021; Hernando et al., 2019) that contribute to the aetiology and maintenance of this problem (Aouad et al., 2021; Brown et al., 2016). Therefore, the behaviours characteristic of EDs can be employed as dysfunctional coping mechanisms to regain control over stressful circumstances (Schlegl et al., 2020). More specifically, findings suggest that individuals with an ED predominantly employ coping strategies based on self-criticism and social isolation. Furthermore, the importance of further research has been pointed out because coping strategies play an important role in the prognosis and treatment of ED (Jáuregui et al., 2009), especially social isolation. Empirical studies suggest that social isolation and low sense of social support increase ED symptomatology and have a detrimental impact on recovery (Branley-Bell \& Talbot, 2020; Cooper et al., 2020; Hajek \& König, 2021; Martins et al., 2019). This may be because social isolation promotes increased maladaptive eating habits and body dissatisfaction (Robertson et al., 2021). Therefore, it has been noted that social support and adaptive social functioning are key to a more effective and complete recovery (Barkus \& Badcock, 2019; Harney et al., 2014).

Likewise, the empirical literature has noted that eating disorders increase the probability of suffering intimate partner violence (IPV) throughout life (Bundock et al., 2013; Pichiule et al., 2014). Therefore, the prevalence of IPV among individuals with eating disorders is high (Huston et al., 2019). However, the mechanisms underlying this relationship are unclear. Previous studies have found that social isolation and fear of loneliness are vulnerability factors for staying in violent relationships (Hendy et al., 2003). Despite this, the role they play in the relationship between EDs and IPV has not benn established. Consequently, their study is of utmost importance to design early and effective prevention and intervention programs (Bauer et al., 2017).

In recent years, this line of research examining the relationship between eating disorders and IPV is gaining relevance due to its clinical and prognostic implications. Therefore, the present study's main objectives were to analyse the relationships between core symptoms traversing eating disorders, explore the mediating role of fear of loneliness in the relationship between the behavioural characteristics of EDs and IPV, and explore the moderating role of social isolation in the relationship between fear of loneliness and IPV. Based on the aforementioned literature, the hypotheses of the present study were: (i) the core symptoms traversing Eds will have a significant direct effect on received partner violence; and (ii) the core symptoms traversing EDs will have a significant indirect effect on received partner violence through the mediating role of fear of loneliness and the moderating role of social isolation. 


\section{Method \\ Participants}

The sample comprised 683 emerging Spanish adults who participated in a cross-sectional survey study. The average age of the participants was 21.14 years old $(S D=2.72 ; 78 \%$ female and $22 \%$ male). The participants were mostly students $(80.1 \%)$ and workers $(19.3 \%)$. The remaining participants were unemployed (0.6\%).

\section{Instruments}

Eating disorder characteristics. The Eating Disorders Inventory-2 (EDI-2; Garner, 1998) was used to assess clinically relevant behaviours and psychological traits that accompany eating disorders. It consists of 91 items divided into 11 scales (obsession with thinness, bulimia, body dissatisfaction, inefficacy, perfectionism, interpersonal distrust, interoceptive awareness, fear of maturity, asceticism, impulsivity and social insecurity). All items (e.g., I tend to eat when I am upset; I find it difficult to express my emotions to others; I think my stomach is too big) are rated on a six-point scale from 0 ("Never") to 5 ("Always"). The higher the scores obtained on each scale, the greater the manifestations of the trait evaluated. The internal consistency (Cronbach's a) of the subscales in the present study ranged from .73 to .90 .

Fear of loneliness. The fear of loneliness subscale from the Emotional Dependency Questionnaire (CDE; Lemos \& Londoño, 2006) was used to assess fear of Ioneliness. All items (e.g., I feel helpless when I am alone; I feel a strong sense of emptiness when I am alone; I cannot tolerate loneliness) are rated on a sixpoint scale from 1 ("Completely untrue of me") to 6 ("Describes me perfectly"). The higher the score obtained, the greater the fear of loneliness. The internal consistency in the present sample was $\alpha=.82$.

Social avoidance. The Coping Strategies Inventory (CSl; Tobin et al., 1989) was used to assess social avoidance. The scale assesses eight styles of coping with stressful situations by means of 41 items (problem solving, cognitive restructuring, social support, emotional expression, problem avoidance, desiderative thinking, social withdrawal, self-criticism). All items (e.g., I avoided being with people; I didn't let anyone know how I felt) are rated on a five-point scale from 0 ("Not at all") to 4 ("Completely"). The higher the score obtained, the greater the social avoidance. The internal consistency in the present sample was a $=.74$.

Received violence. The Violence Received, Exercised and Perceived in Youth and Adolescent Dating Relationships Scale (VREP; Urbiola et al., 2020) was used to assess received violence. The scale comprises 28 items including five violence subscales (physical violence, sexual violence, social psychological violence, psychological violence humiliation-coercion, and psychological violence control-jealousy) and encompassing three aspects of violence: received, exerted, and perceived. For violence received and exercised, items (e.g., My boyfriend/girlfriend tells me to change the way I dress, do my hair... and criticizes it; My boyfriend/girlfriend wants to know where I am at all times and who I am with; My boyfriend/girlfriend has run out of friends because I didn't like them and told him/her not to be with them) are rated on a six-point scale (0 "Never", 1 "Once", 2 "From 2 to 5 times", 3 "From 6 to 10 times", 4 "From 11 to 15 times" and 5 "More than 15 times") and for perceived violence items (e.g., My boyfriend/girlfriend has forced me to have sex (any kind of oral or penetration) when I did not want to. Is this violence?) are rated on a five-point scale ( 1 "No violence", 2 "Little violent", 3 "Somewhat violent", 4 "Quite violent" and 5 "Very violent"). In addition, participants indicate whether they consider the situations mentioned to be violence. The higher the score obtained, the greater the received violence. In the present study, the violence received was of particular interest in the analysis. The internal consistency of the five subscales of received violence ranged from $a=.82$ to .89 .

\section{Procedure}

Participants were recruited through two channels: online and face-to-face. For the online recruitment, surveys were made available through an online platform (surveymonkey.com). Participation was promoted through different social networks and advertisements on research websites. For the face-to-face recruitment, participants were recruited at the Complutense University of Madrid and at gyms in the Madrid community. The only exclusion criterion was being under 18 years of age. All participants gave their informed consent by pointing or clicking on a button indicating that they had read the study information and agreed to participate voluntarily. The study followed the ethical principles of the 2013 Helsinki Declaration and was approved by the research team's university ethics committee.

\section{Statistical analysis}

The analyses of the data was carried out using Mplus 7.0 (Muthén \& Muthén, 2012). The hypothesized model was tested by path analysis using maximum likelihood. Following the model described in Fig. 1, the model included the eating disorder characteristics (i.e. obsession for thinness, bulimia, body dissatisfaction, ineffectiveness, perfectionism, interpersonal distrust, interoceptive awareness, fear of maturity, asceticism, impulsiveness and social insecurity) as independent variables, received violence as the dependent variable (i.e., physical, sexual, psychological humiliation-coercion, psychological control-jealousy and social), the fear of loneliness as the mediator, and social withdrawal as the moderator in the relationship between the mediator and the dependent variables. Gender and age were included as controls in the model.

The adequacy of the proposed model was analyzed according to the following model fit indicators: ratio of chi-square $\left(\chi^{2}\right)$ and the degrees of freedom, the comparative fit index (CFI), the Tucker-Lewis index (TLI), the root mean squared error of approximation (RMSEA), and the standardized root mean square residual (SRMR). Values of $\chi^{2} / \mathrm{df}$ of $<3.0, \mathrm{CFI}$ and TLI $\geq .90$, and RMSEA and SRMR $<.08$ were considered indicators of good fit (Hu \& Bentler, 1999 ).

In order to test the moderated mediation, the direct effect of EDCs (eating disorder characteristics) on the dependent variables was included, and the variables of the products were standardized. Additionally, the analysis adapted the code provided by Stride et al. (2015) in Model 1 and Model 14 to test the simple slopes of the direct and indirect effects. All moderations and moderated-mediation were tested at the mean and at $\pm 1.5 \mathrm{SD}$ of the moderator variable. 


\section{Results}

First, the descriptive statistics of the sample and the correlations between the study variables were calculated (see Tables 1 and 2). Some of the EDCs were not significantly correlated with any of the received violence indicators (i.e., bulimia, body dissatisfaction and fear of maturity). Fear of loneliness and social withdrawal were significantly correlated with all variables.

Table 1.

Descriptive statistics of the study variables $(n=683)$

\begin{tabular}{|c|c|c|c|c|}
\hline \multirow[b]{2}{*}{ Variables } & \multicolumn{4}{|c|}{ Descriptives } \\
\hline & M & SD & Minimum & Maximum \\
\hline \multicolumn{5}{|l|}{ Eating disorder characteristics } \\
\hline Obsession for thinness & 13.68 & 9.30 & 0 & 35 \\
\hline Bulimia & 9.10 & 6.08 & 0 & 32 \\
\hline Body dissatisfaction & 20.39 & 7.18 & 2 & 41 \\
\hline Ineffectiveness & 15.14 & 8.78 & 0 & 48 \\
\hline Perfectionism & 11.60 & 5.67 & 0 & 30 \\
\hline Interpersonal distrust & 11.92 & 5.97 & 0 & 32 \\
\hline Interoceptive awareness & 17.74 & 8.76 & 0 & 45 \\
\hline Fear of maturity & 19.18 & 6.43 & 2 & 40 \\
\hline Asceticism & 12.31 & 6.20 & 0 & 40 \\
\hline Impulsiveness & 14.44 & 8.44 & 0 & 55 \\
\hline Social insecurity & 13.84 & 6.51 & 0 & 40 \\
\hline Fear of loneliness & 5.53 & 2.99 & 2 & 18 \\
\hline Social withdrawal & 5.80 & 4.11 & 0 & 20 \\
\hline \multicolumn{5}{|l|}{ Received violence } \\
\hline Physical & 0.21 & 0.55 & 0 & 5 \\
\hline Sexual & 0.33 & 0.73 & 0 & 5 \\
\hline Psychological humiliation-coercion & 0.41 & 0.82 & 0 & 5 \\
\hline Psychological control-jealousy & 0.60 & 0.96 & 0 & 5 \\
\hline Social & 0.28 & 0.67 & 0 & 4.6 \\
\hline
\end{tabular}

Second, the path analysis of the hypothesized model was performed. All model fit indicators showed a good fit of the model, $\chi^{2} / \mathrm{df}=2.26, \mathrm{CFI}=.99, \mathrm{TLI}=.95$, RMSEA $=.04$, SRMR $<.01$. As displayed in Table 3, the model showed that ineffectiveness, fear of maturity, and impulsiveness were the EDCs related to fear of Ioneliness. Fear of loneliness had no direct significant effect on any of the variables of received violence. However, the interaction effects indicated that there was a significant moderated effect of fear of loneliness on physical, psychological humiliation-coercion, and social received violence depending on the levels of social withdrawal. 
Table 2.

Bivariate correlations between the study variables

\begin{tabular}{|c|c|c|c|c|c|c|c|c|c|c|c|c|c|c|c|c|c|}
\hline & Correl & tions & & & & & & & & & & & & & & & \\
\hline Variables & 1 & 2 & 3 & 4 & 5 & 6 & 7 & 8 & 9 & 10 & 11 & 12 & 13 & 14 & 15 & 16 & 1 \\
\hline \multicolumn{18}{|l|}{$\begin{array}{l}\text { Eating disorder } \\
\text { characteristics }\end{array}$} \\
\hline $\begin{array}{l}\text { 1. Obsession } \\
\text { for thinness }\end{array}$ & $(.90)$ & & & & & & & & & & & & & & & & \\
\hline 2. Bulimia & $.41 \star \star$ & $(.80)$ & & & & & & & & & & & & & & & \\
\hline $\begin{array}{l}\text { 3. Body } \\
\text { dissatisfaction }\end{array}$ & $.58^{\star \star}$ & $.32^{\star \star}$ & $(.89)$ & & & & & & & & & & & & & & \\
\hline $\begin{array}{l}4 . \\
\text { Ineffectiveness }\end{array}$ & $.45^{\star \star}$ & $.39 * \star$ & $.35^{\star \star}$ & $(.88)$ & & & & & & & & & & & & & \\
\hline $\begin{array}{l}5 . \\
\text { Perfectionism }\end{array}$ & $.27^{\star \star}$ & $.39 \star \star$ & $.15^{\star \star}$ & $.26^{\star \star}$ & $(.73)$ & & & & & & & & & & & & \\
\hline $\begin{array}{l}6 . \\
\text { Interpersonal } \\
\text { distrust }\end{array}$ & $.15^{\star \star}$ & $.14^{\star \star}$ & $.17^{\star \star}$ & $.53^{* *}$ & $.10 \star \star$ & $(.73)$ & & & & & & & & & & & \\
\hline $\begin{array}{l}\text { 7. Interoceptive } \\
\text { awareness }\end{array}$ & $.49 \star *$ & $.56^{\star \star}$ & $.38^{* \star}$ & $.65^{\star \star}$ & $.39 \star \star$ & $.46^{\star \star}$ & $(.84)$ & & & & & & & & & & \\
\hline $\begin{array}{l}\text { 8. Fear of } \\
\text { maturity }\end{array}$ & $.23^{\star \star}$ & $.17^{\star \star}$ & $.19 \star \star$ & $.35^{\star \star}$ & $.20 * \star$ & $.26 * \star$ & $.40 \star \star$ & (.73) & & & & & & & & & \\
\hline 9. Asceticism & $.44^{\star \star}$ & $.57^{\star \star}$ & $.34^{\star \star}$ & $.49 * \star$ & $.48^{\star \star}$ & $.17 \star \star$ & $.60 * \star$ & $.25^{\star \star}$ & $(.73)$ & & & & & & & & \\
\hline $\begin{array}{l}10 . \\
\text { Impulsiveness }\end{array}$ & $.35^{\star}$ & $.52^{\star \star}$ & $.29 \star \star$ & $.52^{\star \star}$ & $.39 \star \star$ & $.24^{\star \star}$ & $.67 \star \star$ & $.28 * \star$ & $.67 * \star$ & $(.82)$ & & & & & & & \\
\hline $\begin{array}{l}\text { 11. Social } \\
\text { insecurity }\end{array}$ & $.21^{\star \star}$ & $.20 * \star$ & $.20 * \star$ & $.66^{\star \star}$ & $.13^{\star *}$ & $.67 * \star$ & $.43^{\star *}$ & $.26^{\star \star}$ & $.27^{\star \star}$ & $.38^{* *}$ & $(.79)$ & & & & & & \\
\hline $\begin{array}{l}\text { 12. Fear of } \\
\text { loneliness }\end{array}$ & $.22^{\star \star}$ & $.26^{\star \star}$ & $.20 \star \star$ & $.37 \star \star$ & $.23^{\star \star}$ & $.16^{\star \star}$ & $.34^{\star \star}$ & $.25^{\star \star}$ & $.35^{\star \star}$ & $.38 * \star$ & $.24^{\star \star}$ & $(.82)$ & & & & & \\
\hline $\begin{array}{l}\text { 13. Social } \\
\text { withdrawal }\end{array}$ & $.19 \star \star$ & $.23^{\star \star}$ & $.17^{\star \star}$ & $.39 *$ & $.22^{\star \star}$ & $.42^{\star \star}$ & $.38 * \star$ & $.21 * \star$ & $.31 * \star$ & $.30 * *$ & $.43^{\star \star}$ & $.19 \star \star$ & $(.74)$ & & & & \\
\hline \multicolumn{18}{|l|}{$\begin{array}{l}\text { Received } \\
\text { violence }\end{array}$} \\
\hline 14. Physical & 0.05 & 0.04 & -0.03 & 0.04 & 0.06 & 0.01 & $.10 \star \star$ & 0.07 & $.09 *$ & $.11^{\star \star}$ & 0.05 & $.12^{\star \star}$ & $.10^{\star \star}$ & $(.82)$ & & & \\
\hline 15.Sexual & $.13^{\star \star}$ & 0.04 & 0.02 & $.11^{\star \star}$ & $.09 *$ & 0.04 & $.11^{\star \star}$ & 0.01 & $.12^{\star \star}$ & $.15^{\star \star}$ & $.09 *$ & $.09 *$ & $.11^{\star \star}$ & $.53^{\star \star}$ & $(.88)$ & & \\
\hline $\begin{array}{l}16 . \\
\text { Psychological } \\
\text { humiliation- } \\
\text { coercion }\end{array}$ & $.07 *$ & 0.03 & 0.01 & $.09 * \star$ & $.10 \star \star$ & 0.03 & $.07 *$ & 0.02 & $.12^{\star \star}$ & $.14^{\star \star}$ & $.10 \star \star$ & $.09 *$ & $.08^{*}$ & $.64^{\star \star}$ & $.67 \star \star$ & $(.88)$ & \\
\hline $\begin{array}{l}17 . \\
\text { Psychological } \\
\text { control- } \\
\text { jealousy }\end{array}$ & $.10 \star \star$ & 0.06 & 0.03 & $.08^{*}$ & $.11^{\star \star}$ & 0.04 & $.11^{\star \star}$ & 0.03 & $.14^{\star \star}$ & $.19 * \star$ & $.09 *$ & $.11^{\star \star}$ & $.12^{\star \star}$ & $.57 \star \star$ & $.64^{\star \star}$ & $.81^{\star \star}$ & (. \\
\hline 18. Social & $.08^{*}$ & 0.03 & 0.03 & $.12^{\star \star}$ & 0.07 & $.08^{\star}$ & $.10 \star \star$ & 0.02 & $.11 \star \star$ & $.13^{\star \star}$ & $.15^{\star \star}$ & $.09 *$ & $.11 \star \star$ & $.60 \star *$ & $.65^{\star \star}$ & $.86^{\star \star}$ & $\varepsilon$ \\
\hline
\end{tabular}

Based on the simple slopes of the interactions, higher fear of loneliness was significantly related to more physical violence $(\beta=0.16, \mathrm{SE}=0.03, p<.001)$ and psychological humiliation-coercion received violence $(\beta=0.11, \mathrm{SE}=0.05, p=.028)$ when the social withdrawal was high, but there was no significant relationship when the social withdrawal was low (physical: $\beta=-0.07, \mathrm{SE}=0.03, p=.063$; psychological humiliation-coercion: $\beta=-0.06, \mathrm{SE}=0.05, p=.281$ ) or medium (physical: $\beta=0.16, \mathrm{SE}=0.03, p=.053$; psychological humiliation-coercion: $\beta=0.02, \mathrm{SE}=0.03, p=.444$ ).

Regarding social received violence, the simples slopes indicated that greater fear of loneliness was significantly related to lower social received violence when the social withdrawal was low $(\beta=-0.19, \mathrm{SE}=0.04, p=.043)$, but was related to greater social violence when the social withdrawal was high $(\beta=0.13, \mathrm{SE}=$ $0.04, p=.002)$. The relationship at medium levels of social withdrawal was not significant $(\beta=0.01, \mathrm{SE}=0.02, p=.499)$.

As a final step, the moderated mediation of the EDC was tested on the variables of received violence (see Table 4 and Fig. 2). The indirect effects of ineffectiveness, fear of maturity and impulsiveness on physical violence, and social received violence, through fear of loneliness, were significant only at high social withdrawal levels. However, none of the indirect effects on psychological humiliation-coercion received violenece was significant, although a tendency was observed for high social withdrawal levels. 
Table 3.

Standardized direct and interaction effects of the model based on path analysis

\begin{tabular}{|c|c|c|c|c|c|c|c|c|c|c|c|c|}
\hline & \multicolumn{12}{|c|}{ Dependent variables } \\
\hline & & & Received & olence & & & & & & & & \\
\hline \multirow[t]{2}{*}{$\begin{array}{l}\text { Independent } \\
\text { variables }\end{array}$} & \multicolumn{2}{|c|}{ Fear of loneliness } & \multicolumn{2}{|l|}{ Psysical } & \multicolumn{2}{|l|}{ Sexual } & \multicolumn{2}{|c|}{$\begin{array}{l}\text { Psychological } \\
\text { humiliation-coercion }\end{array}$} & \multicolumn{2}{|c|}{$\begin{array}{l}\text { Psychological } \\
\text { control-jealousy }\end{array}$} & \multicolumn{2}{|l|}{ Social } \\
\hline & $\beta$ & $S E$ & $\beta$ & $S E$ & $\beta$ & $S E$ & $\beta$ & $S E$ & $\beta$ & $S E$ & $\beta$ & $S E$ \\
\hline \multicolumn{13}{|l|}{$\begin{array}{l}\text { Eating disorder } \\
\text { characteristics }\end{array}$} \\
\hline $\begin{array}{l}\text { Obsession for } \\
\text { thinness }\end{array}$ & -0.03 & 0.04 & 0.08 & 0.05 & 0.14 ** & 0.05 & 0.06 & 0.05 & $0.10 *$ & 0.05 & 0.06 & 0.05 \\
\hline Bulimia & 0.02 & 0.04 & -0.06 & 0.04 & -0.08 & 0.05 & -0.08 & 0.05 & $-0.09 *$ & 0.04 & -0.08 & 0.05 \\
\hline $\begin{array}{l}\text { Body } \\
\text { dissatisfaction }\end{array}$ & 0.05 & 0.04 & $-0.12^{*}$ & 0.04 & $-0.09 *$ & 0.04 & -0.05 & 0.04 & -0.04 & 0.04 & 0.04 & 0.04 \\
\hline Ineffectiveness & 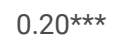 & 0.05 & -0.12 & 0.06 & 0.01 & 0.06 & $<-0.01$ & 0.06 & -0.08 & 0.06 & $<0.01$ & 0.06 \\
\hline Perfectionism & 0.05 & 0.04 & $<0.01$ & 0.04 & 0.04 & 0.04 & 0.06 & 0.04 & 0.04 & 0.04 & 0.03 & 0.04 \\
\hline $\begin{array}{l}\text { Interpersonal } \\
\text { distrust }\end{array}$ & -0.03 & 0.04 & -0.08 & 0.05 & -0.03 & 0.05 & -0.04 & 0.05 & -0.02 & 0.05 & -0.03 & 0.05 \\
\hline $\begin{array}{l}\text { Interoceptive } \\
\text { awareness }\end{array}$ & -0.04 & 0.06 & $0.14^{\star}$ & 0.06 & $<0.01$ & 0.06 & -0.03 & 0.06 & 0.01 & 0.06 & $<0.01$ & 0.06 \\
\hline Fear of maturity & $0.12^{\star *}$ & 0.03 & 0.03 & 0.04 & -0.06 & 0.04 & -0.03 & 0.04 & -0.03 & 0.04 & -0.05 & 0.04 \\
\hline Asceticism & 0.09 & 0.05 & $<0.01$ & 0.05 & $<0.01$ & 0.05 & 0.05 & 0.05 & $<0.01$ & 0.05 & 0.05 & 0.05 \\
\hline Impulsiveness & $0.17^{\star \star}$ & 0.05 & 0.03 & 0.05 & $0.13^{\star}$ & 0.05 & 0.11 & 0.05 & $0.18^{\star \star}$ & 0.05 & 0.06 & 0.05 \\
\hline Social insecurity & $<0.01$ & 0.05 & 0.07 & 0.05 & 0.02 & 0.06 & 0.08 & 0.06 & 0.05 & 0.05 & $0.12^{\star}$ & 0.05 \\
\hline Fear of Ioneliness & & & 0.08 & 0.04 & 0.03 & 0.04 & 0.03 & 0.04 & 0.04 & 0.04 & 0.02 & 0.04 \\
\hline Social withdrawal & & & 0.06 & 0.04 & 0.07 & 0.04 & 0.03 & 0.04 & 0.07 & 0.04 & 0.04 & 0.04 \\
\hline $\begin{array}{l}\text { Fear of lonelines X } \\
\text { Social withdrawal }\end{array}$ & & & $0.15^{\star \star \star}$ & 0.03 & 0.03 & 0.03 & $0.07 *$ & 0.03 & 0.06 & 0.03 & $0.12^{\star \star}$ & 0.03 \\
\hline$r^{2}$ & $.21^{\star \star \star \star}$ & & $.07^{\star \star \star \star}$ & & $.05^{\star \star}$ & & $.04^{\star \star}$ & & $.06^{\star \star \star}$ & & $.05^{\star \star}$ & \\
\hline
\end{tabular}

\section{Table 4.}

Moderated indirect effects of ineffectiveness, fear of maturity and impulsiveness on physical, psychological humiliation-coertion and social received violence through fear of loneliness 


\begin{tabular}{|c|c|c|c|c|c|c|c|}
\hline \multirow[b]{3}{*}{ Independent variables } & \multirow[b]{3}{*}{ Level of the moderator } & \multicolumn{6}{|c|}{$\begin{array}{l}\text { Dependent variables } \\
\text { (Received violence) }\end{array}$} \\
\hline & & \multicolumn{2}{|c|}{ Physical } & \multicolumn{2}{|c|}{ Psychological humiliation-coercion } & \multicolumn{2}{|c|}{ Social } \\
\hline & & $z$ & $p$ & $z$ & $p$ & $z$ & $p$ \\
\hline & Low social withdrawal & -1.65 & .099 & -1.03 & .302 & -1.76 & .078 \\
\hline \multirow[t]{3}{*}{ Innefectiveness } & Average social withdrawal & 1.70 & .089 & 0.74 & .454 & 0.66 & .507 \\
\hline & High social withdrawal & $2.81^{\star}$ & .005 & 1.86 & .062 & $2.34 *$ & .019 \\
\hline & Low social withdrawal & -1.60 & .109 & -1.02 & .308 & -1.71 & .088 \\
\hline \multirow[t]{3}{*}{ Fear of maturity } & Average social withdrawal & 1.65 & .099 & 0.74 & .456 & 0.66 & .509 \\
\hline & High social withdrawal & $2.61^{\star \star}$ & .009 & 1.80 & .071 & $2.22^{\star}$ & .026 \\
\hline & Low social withdrawal & -1.61 & .106 & -1.02 & .306 & -1.72 & .085 \\
\hline \multirow[t]{2}{*}{ Impulsiveness } & Average social withdrawal & 1.66 & .096 & 0.74 & .456 & 0.66 & .508 \\
\hline & High social withdrawal & $2.66^{\star *}$ & .008 & 1.82 & .068 & $2.25^{\star}$ & .024 \\
\hline
\end{tabular}

\section{Discussion}

The main objective of the present study was to analyse the association between core symptoms traversing eating disorders, and explore the role of fear of loneliness and social isolation in relation to behavioural eating disorder characteristics (EDCs) and intimate partner violence (IPV) received. First, it was hypothesised that core symptoms traversing EDs would have a significant direct effect on received partner violence. Results showed that some of the EDCs were not significantly associated with any of the received violence indicators (e.g., bulimia, body dissatisfaction, and fear of maturity). However, other indicators such as obsession for thinness, ineffectiveness, perfectionism, interoceptive awareness, asceticism, impulsiveness, and social insecurity were all significantly and positively related to received violence. These results are in accordance to previous scientific literature that eating disorders increase likelihood of IPV among both females and males (Bundock et al., 2013; Pichiule et al., 2014). Although EDs have traditionally been considered female disorders, recent evidence suggests that it is not uncommon among males, and that males can present similar severe ED symptoms. In fact, there are specific risk factors for developing ED in young and adolescent males, such as body image concerns related to muscularity and sexual orientation (Gorrell \& Murray, 2019). As aforementioned, eating disorders can emerge as maladaptive coping mechanisms that enable individuals to regain control over adverse situations, as can be receiving violence (Schlegl et al., 2020; Wong \& Chang, 2016). Another factor associated with EDs and violence exposure among both sexes is social isolation, which has been associated with adoption of unhealthy weight control practices (Martins et al., 2019).

With the aim of exploring more deeply the role of social aspects, the second hypothesis was that core symptoms traversing EDs would have a significant indirect effect on received partner violence through the mediating role of fear of loneliness and the moderating role of social isolation. On the one hand, results showed that ineffectiveness, fear of maturity, and impulsivity were the behavioural EDCs predominantly related to fear of loneliness. Fear of loneliness had no direct significant effect on any of the received violence variables. Nevertheless, interaction effects indicated a moderately significant influence of fear of loneliness on physical violence, psychological humiliation-coercion, and social received violence as a function of levels of social withdrawal.

It was also found that the indirect effects of ineffectiveness, fear of maturity, and impulsiveness on physical and social received violence, through fear of loneliness, were significant only at high social withdrawal levels. Results refine the understanding of the relationship between social withdrawal and the development of eating disorders in individuals exposed to partner violence. Individuals suffering loneliness appear to be more susceptible to developing disordered eating patterns (Wright \& Pritchard, 2009). For instance, the pandemic and subsequent social restrictions have limited and deprived individuals of social interaction and therefore, of social support and similar coping strategies in facing this unprecedented situation (Monteleone et al., 2021). Therefore, eliminating social protection factors when coping with adverse events could increase risk and symptoms of ED (Rodgers et al., 2020). In this sense, loneliness has been conceived as a mediator between emotional dysregulation and eating disorders-related psychopathology (Southward et al., 2014).

This lack of perceived social support associated with the exposure to partner violence could culminate in many psychological health consequences, such as depression, post-traumatic stress, anxiety, and eating disorders, among other mental health illnesses (Mazza et al., 2021). Low levels of social support have been related to increased risk of ED among women exposed to IPV. Social support has shown protective effects against ED by decreasing levels of anxiety and promoting mechanisms related to functional coping strategies (Schirk et al., 2015). However, IPV-exposure and trauma history can precede the development of ED symptoms. The extant literature highlights the presence of childhood abuse among individuals suffering IPV and Eds. Children who have experienced exposure to violent situations appear to be more susceptible to developing Eds (Bundock et al., 2013; Kimber et al., 2017).

Other studies have identified specific aspects related to altered-eating behaviours and IPV-exposure including somatization, avoiding abuse, coping, self-harm, and challenging abusive partners (Wong \& Chang, 2016). All of these aspects support the notion that ED-related behaviours are used as ways to cope with adverse and stressful situations such as received violence. This could be important information for therapists who work with those experiencing IPV and who develop interventions for patients with clinical symptoms of eating disorders. Results emphasize the importance of understanding the vulnerability and

Page 7/10 
absence of coping resources among individuals who suffer IPV and develop Eds, with the aim of designing interventions focused on the promotion of coping through seeking social support and avoiding isolation.

The present study has some limitations that should be noted. First, the cross-sectional design employed in the present study does not allow determining conclusions in terms of causality. Therefore, longitudinal studies would be needed to determine any casual inference among different variables examined in the present study. Secondly, the sample in the present study was limited to emerging adults, with an average age of 21 years old, therefore results cannot be generalized to other age groups. In future research, it would be interesting to extend the study to other age populations, with the aim of exploring differences in ED-behaviour patterns and IPV related to social isolation aspects in other developmental phases. In addition, the present study did not explored differences by sex in the variables of interest. Efforts to increase the number of male participants would be of utility with the objective of homogenizing the sample and analysing differences in ED patterns and different symptoms related to received violence in relationships.

Overall, the results of the present study demonstrate the role of social-related aspects in the relationship between eating disorders and IPV. It is suggested that individuals exposed to violent situations in relationships may develop ED-related symptoms as a way of coping adverse situations. However, this relationship is not direct, and it appears that underlying mechanisms related to fear to loneliness and social withdrawal prevent the developing of coping resources for facing received violence. Future research should focus on finding ways of empowering victims through increasing social support and promoting resilience and adaptive coping resources as ways to reduce exposure to violent situations.

\section{Declarations}

Funding: The present study was funded by a research grant for the project "Psychological factors mediating the relationship between insecure attachment, behavioural addictions and staying in violent relationships", awarded by the Basque Government.

\section{References}

1. Aouad P, Hay P, Foroughi N, Cosh SM, Mannan H (2021) Associations between defence-style, eating disorder symptoms, and quality of life in community sample of Women: A Longitudinal Exploratory Study. Front Psychol 12:671652. https://doi.org/10.3389/fpsyg.2021.671652

2. Arnett JJ, Žukauskienė R, Sugimura K (2014) The new life stage of emerging adulthood at ages 18-29 years: Implications for mental health. The Lancet Psychiatry 1(7):569-576. http://dx.doi.org/10.1016/S2215-0366(14)00080-7

3. Barkus E, Badcock JC (2019) A transdiagnostic perspective on social anhedonia. Front Psychiatry 10:216. https://doi.org/10.3389/fpsyt.2019.00216

4. Bauer S, Kindermann SS, Moessner M (2017) Prevention of eating disorder: A review. Z fur Kinder und Jugendosychiatrie und Psychoterapie 45(5):403413. https://doi.org/10.1024/1422-4917/a000506

5. Bhattacharya A, DeFilipp L, Timko CA (2020) Feeding and eating disorders. Handb Clin Neurol 175:387-403. https://doi.org/10.1016/B978-0-444-641236.00026-6

6. Branley-Bell D, Talbot CV (2020) Exploring the impact of the COVID-19 pandemic and UK lockdown on individuals with experience of eating disorders. J Eat Disorders 8:44. https://doi.org/10.1186/s40337-020-00319-y

7. Brown SM, Opitz MC, Peebles Al, Sharpe H, Duffy F, Newman E (2021) A qualitative exploration of the impact of COVID-19 on individuals with eating disorders in the UK. Appetite 156:104977. https://doi.org/10.1016/j.appet.2020.104977

8. Brown JM, Selth S, Stretton A, Simpson S (2016) Do dysfunctional coping modes mediate the relationship between perceived parenting style and disordered eating behaviours? J Eat Disorders 4:21. https://doi.org/10.1186/s40337-016-0123-1

9. Bundock L, Howard LM, Trevillion K, Malcom E, Feder G, Oram S (2013) Prevalence and risk of experiences of intimate partner violence among people with eating disorders: a systematic review. J Psychiatr Res 47(9):1134-1142. https://doi.org/10.1016/j.jpsychires.2013.04.014

10. Cacioppo JT, Cacioppo S (2018) The growing problem of loneliness. The Lancet 3:426. http://dx.doi.org/10.1016/S0140-6736(18)30142-9

11. Cooper M, Reilly EE, Siegel JA, Coniglio K, Sadeh-Sharvit S, Pisetsky EM, Anderson LM (2020) Eating disorders during the COVID-19 pandemic and quarantine: an overview of risks and recommendations for treatment and early intervention. Eat Disord 1-23. https://doi.org/10.1080/

10640266.2020 .1790271

12. Garner DM (1998) Eating Disorder Inventory EDI 2. TEA Ediciones, p A

13. Gorrell S, Murray SB (2019) Eating disorders in males. Child Adolesc Psychiatr Clin N Am 28(4):641-651. https://doi.org/10.1016/ j.chc.2019.05.012

14. Hajek A, König HH (2021) Do lonely and socially isolated individuals think they die earlier? The link between loneliness, social isolation and expectations of longevity based on a nationally representative sample. Psychogeriatrics 21(4):571-576. https://doi.org/10.1111/psyg.12707

15. Han W, Zheng Z, Zhang N (2021) Three mediating pathways of anxiety and security in the relationship between coping style and disordered eating behaviors among Chinese female college students. Neural Plast 21-6. https://doi.org/10.1155/2021/7506754

16. Hay P (2020) Current approach to eating disorders: A clinical update. Intern Med J 50(1):24-29. https://doi.org/10.1111/imj.14691

17. Harney MB, Fitzsimmons-Craft EE, Maldonado CR, Bardone-Cone AM (2014) Negative affective experiences in relation to stages of eating disorder recovery. Eat Behav 15(1):24-30. https://doi.org/10.1016/j.eatbeh.2013.10.016

18. Hendy HM, Eggen D, Gustitus C, McLeod KC, Ng P (2003) Decision to Leave Scale: Perceived reasons to stay in or leave violent relationships. Psychol Women Q 27(2):162-173. https://doi.org/10.1111/1471-6402.00096

19. Hernando A, Pallás R, Cebolla A, García-Campayo J, Hoogendoorn CJ, Roy JF (2019) Mindfulness, rumination, and coping skills in young women with eating disorders: A comparative study with healthy controls. PLoS ONE 14(3):e0213985. https://doi.org/10.1371/journal.pone.0213985

Page $8 / 10$ 
20. Hu LT, Bentler PM (1999) Cutoff criteria for fit indexes in covariance structure analysis: Conventional criteria versus new alternatives. Struct Equ Model 6(1):1-55. https://doi.org/10.1080/10705519909540118

21. Huston JC, Grillo AR, Iverson KM, Mitchell KS, Boston Healthcare System (2019) Associations between disordered eating and intimate partner violence mediated by depression and posttraumatic stress disorder symptoms in a female veteran sample. Gen Hosp Psychiatry 58:77-82.

https://doi.org/10.1016/ j.genhosppsych.2019.03.007

22. Jagielska G, Kacperska I (2017) Outcome, comorbidity and prognosisin anorexia nervosa. Psychiatr Pol 51(2):205-218. https://doi.org/10.12740/PP/64580

23. Jáuregui I, Estébanez S, Santiago MJ, Álvarez E, Garrido O (2009) Coping strategies in eating disorders. Eur Eat Disorders Rev 17(3):220-226. https://doi.org/10.1002/erv.920

24. Johnson D, Dupuis G, Piche J, Clayborne Z, Colman I (2018) Adult mental health outcomes of adolescent depression: A systematic review. Depress Anxiety 35(8):700-716. http://dx.doi.org/10.1002/da.22777

25. Kimber M, McTavish JR, Couturier J, Boven A, Gill S, Dimitropoulos G, MacMillan HL (2017) Consequences of child emotional abuse, emotional neglect and exposure to intimate partner violence for eating disorders: a systematic critical review. BMC Psychol 5(1):1-18. https://doi.org/10.1186/s40359-017$0202-3$

26. Lemos M, Londoño NH (2006) Construcción y validación del cuestionario de dependencia emocional en población Colombiana. Acta Colombiana de Psicología 9(2):127-140

27. Maon I, Horesh D, Gvion Y (2020) Siblings of individuals with eating disorders: A review of the literature. Front Psychol 11:604. https://doi.org/10.3389/fpsyt.2020.00604

28. Martins L, Ramos R, Gravas G, Bertazzi R, Machado C (2019) Association between exposure to interpersonal violence and social isolation, and the adoption of unhealthy weight control practices. Appetite 142:104384

29. Mason TB, Heron KE (2016) Do depressive symptoms explain associations between binge eating symptoms and later psychosocial adjustment in young adulthood? Eat Behav 23:126-130. https://doi.org/10.1016/j.eatbeh.2016.09.003

30. Mason TB, Heron KE, Braitman AL, Lewis RJ (2016) A daily diary study of perceived social isolation, dietary restraint, and negative affect in binge eating. Appetite 97:94-100. https://doi.org/10.1016/j.appet.2015.11.027

31. Mazza M, Marano G, Castillo D, Chieffo AG, Monti D, Janiri L, Moccia D, Sani G (2021) Intimate partner violence: A loop of abuse, depression and victimization. World J Psychiatry 11(6):215-221. https://doi.org/10.5498/wjp.v11.i6.215

32. Mehl A, Rohde P, Gau JM, Stice E (2019) Disaggregating the predictive effects of impaired psychosocial functioning on future DSM-5 eating disorder onset in high-risk female adolescents. Int J Eat Disord 52(7):817-824. https://doi.org/10.1002/eat.23082

33. Monteleone AM, Cascino G, Marciello F et al (2021) Risk and resilience factors for specific and general psychopathology worsening in people with Eating Disorders during COVID-19 pandemic: a retrospective Italian multicentre study. Eat Weight Disorders 26(8):2443-2452. https://doi.org/10.1007/s40519020-01097-x

34. Muthén LK, Muthén BO (2012) Mplus user's guide: Statistical analysis with latent variables (Seventh Ed). Muthén \& Muthén, Los Angeles, CA

35. Peaslee M (2012) Loneliness and eating disorders. J Psychol 146(1-2):243-257. https://doi.org/10.1080/00223980.2011.606435

36. Pichiule M, Gandarillas AM, Díez-Gañán L, Sonego M, Ordobás MA (2014) Violencia de pareja en jóvenes de 15 a 16 años de la comunidad de Madrid. Revista Española de Salud Pública 88:639-652

37. Pitman A, Mann F, Johnson S (2018) Advancing our understanding of loneliness and mental health problems in young people. The Lancet Psychiatry 5(12):955-956. http://dx.doi.org/10.1016/S2215-0366(18)30436-X

38. Robertson M, Duffy F, Newman E, Prieto C, Husevin H, Sharpe H (2021) Exploring changes in body image, eating and exercise during the COVID-19 lockdown: A UK survey. Appetite 159:105062. https://doi.org/10.1016/j.appet.2020.105062

39. Rodgers RF, Lombardo C, Cerolini S, Franko DL, Omori M, Fuller-Tyszkiewicz M, Linardon J, Courtet P, Guillaume S (2020) The impact of the COVID-19 pandemic on eating disorder risk and symptoms. Int J Eat Disord 53(7):1166-1170. https://doi.org/10.1002/eat.23318

40. Schirk DK, Lehman EB, Perry AN, Ornstein RM, McCall-Hosenfeld JS (2015) The impact of social support on the risk of eating disorders in women exposed to intimate partner violence. Int J Women's Health 7:919-931. https://doi.org/10.2147/IJWH.S85359

41. Stride CB, Gardner SE, Catley N, Thomas F (2015) Mplus code for mediation, moderation and moderated mediation models (1 to 80). Retrieved February 9 , 2021, from: http://www.figureitout.org.uk

42. Schlegl S, Maier J, Meule A, Voderholzer U (2020) Eating disorders in times of the COVID-19 pandemic-Results from an online survey of patients with anorexia nervosa. Int J Eat Disord 53(11):1791-1800. https://doi.org/10.1002/eat.23374

43. Southward MW, Christensen KA, Fettich KC, Weissman J, Berona J, Chen EY (2014) Loneliness mediates the relationship between emotion dysregulation and bulimia nervosa/binge eating disorder psychopathology in a clinical sample. Eat Weight Disorders 19(4):509-513. https://doi.org/10.1007/s40519013-0083-2

44. Tobin DL, Holroyd KA, Reynolds RV, Wigal JK (1989) The hierarchical factor structure of the Coping Strategies Inventory. Cogn Therapy Res 13:343-361

45. Treasure J, Duarte TA, Schmidt U (2020) Eating disorders. The Lancet 395(10227):899-911. https://doi.org/10.1016/S0140-6736(20)30059-3

46. Urbiola I, Estévez A, Momeñe J (2020) Desarrollo y validación del cuestionario VREP (Violencia Recibida, Ejercida y Percibida) en las relaciones de pareja en adolescentes. Apuntes de Psicología 38(2):103-114

47. Wiedemann AA, Ivezaj V, Barnes RD (2018) Characterizing emotional overeating among patients with and without binge-eating disorder in primary care. Gen Hosp Psychiatry 55:38-43. https://doi.org/10.1016/j.genhosppsych.2018.09.003

Page 9/10 
48. Wright A, Pritchard ME (2009) An examination of the relation of gender, mass media influence, and loneliness to disordered eating among college students. Eat Weight Disorders 14(2-3).

e144-7

.. https://doi.org/10.1007/BF03327813

49. Wong SP, Chang JC (2016) Altered eating behaviors in female victims of intimate partner violence. J interpers Violence 31(20):3490-3505. https://doi.org/10.1177/0886260515585535

\section{Figures}

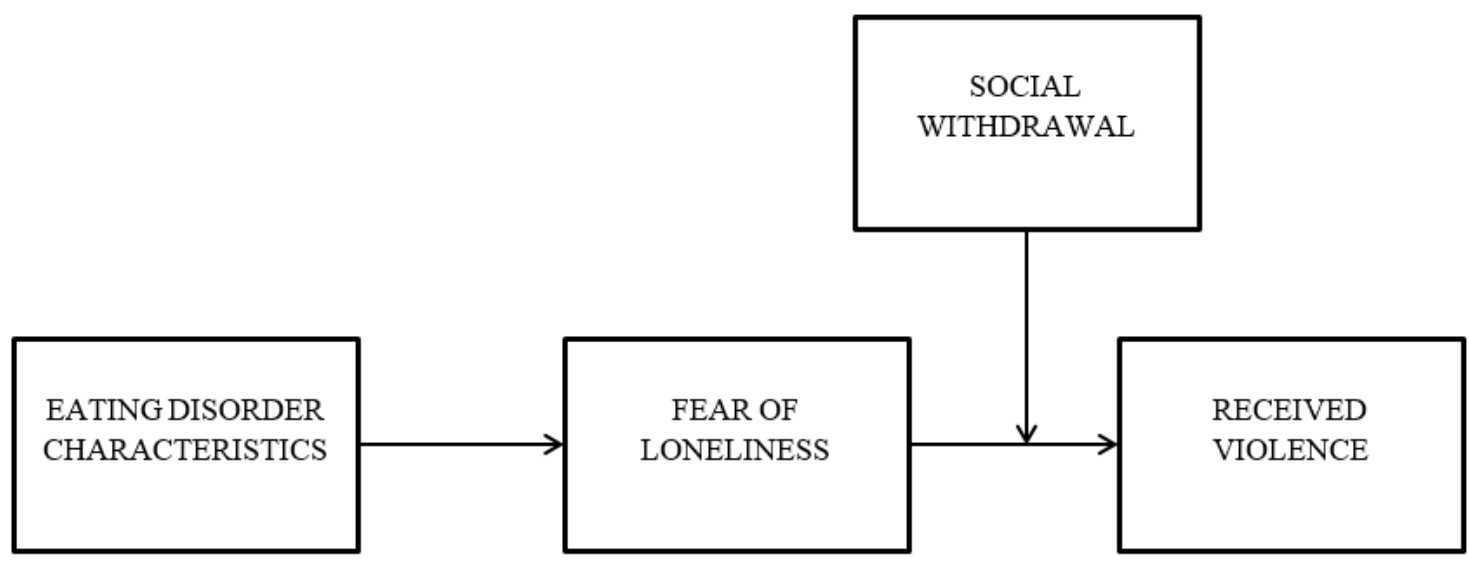

Figure 1

Hypothesized model
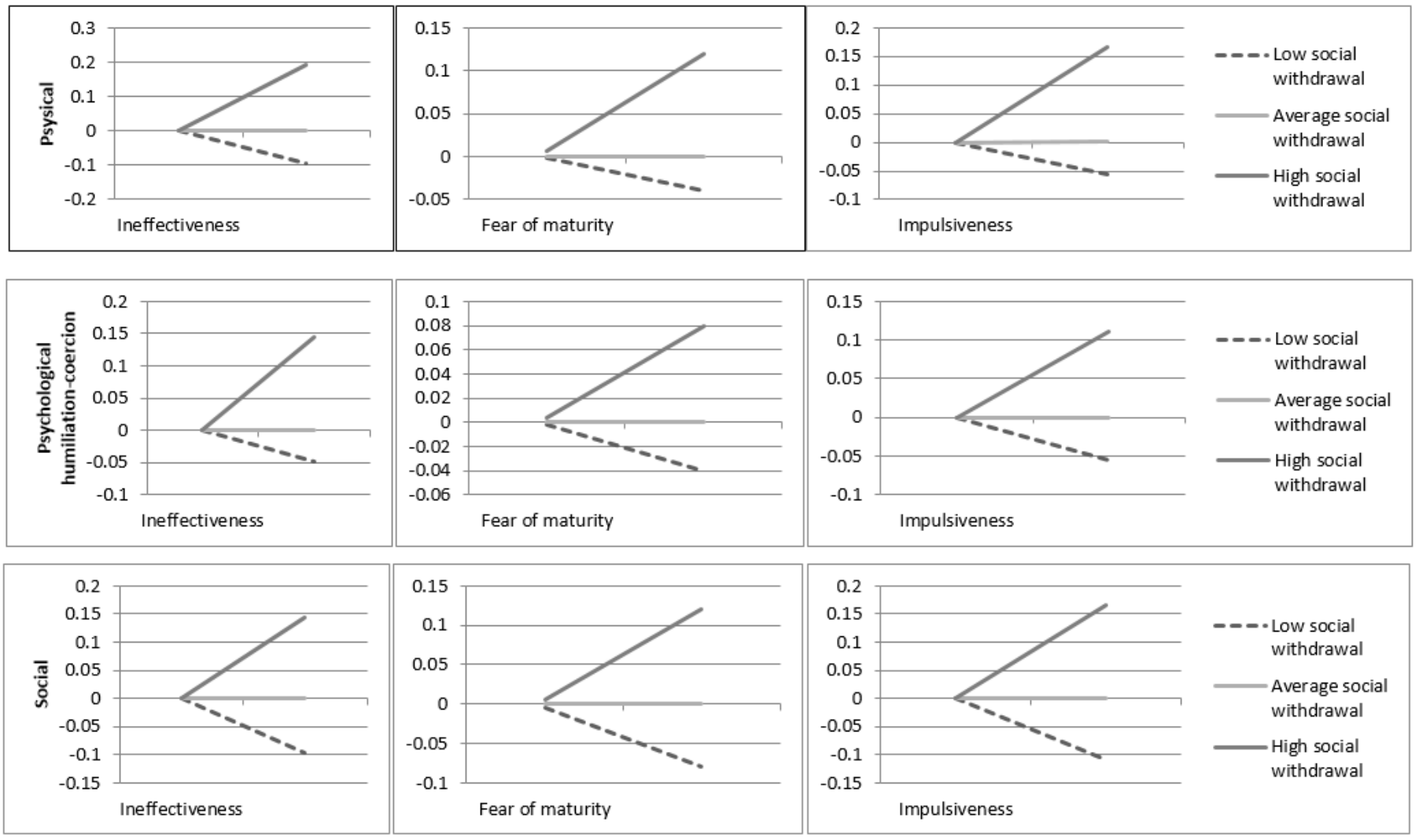

Figure 2

Simple slopes of the indirect moderated effects on received violence 